\title{
Targeting tumour energy metabolism potentiates the cytotoxicity of 5-aminolevulinic acid photodynamic therapy
}

\author{
J P Golding ${ }^{\star, 1}$, T Wardhaugh ${ }^{1}$, L Patrick ${ }^{1}$, M Turner ${ }^{1}$, J B Phillips ${ }^{1}$, J I Bruce ${ }^{1}$ and S G Kimani ${ }^{1,2}$ \\ ${ }^{1}$ Department of Life, Health \& Chemical Sciences, The Open University, Walton Hall, Milton Keynes MK7 6AA, UK and \\ ${ }^{2}$ MGH Wellman Center for Photomedicine, Boston, MA MA02114, USA
}

Background: Cancerous cells usually exhibit increased aerobic glycolysis, compared with normal tissue (the Warburg effect), making this pathway an attractive therapeutic target.

Methods: Cell viability, cell number, clonogenic assay, reactive oxygen (ROS), ATP, and apoptosis were assayed in MCF-7 tumour cells and corresponding primary human mammary epithelial cells (HMEC).

Results: Combining the glycolysis inhibitors 2-deoxyglucose (2DG; $180 \mathrm{~mm}$ ) or lonidamine (300 $\mu \mathrm{M})$ with $10 \mathrm{~J} \mathrm{~cm}^{-2} 5$-aminolevulinic acid (ALA) photodynamic therapy (PDT) increases MCF-7 cytotoxicity (by 3.5-fold to $70 \%$ death after $24 \mathrm{~h}$, and by 10 -fold in 9-day clonogenic assays). However, glycolysis inhibition only slightly increases HMEC PDT cytotoxicity (between two-fold and three-fold to a maximum of $9 \%$ death after $24 \mathrm{~h}$ ). The potentiation of PDT cytotoxicity only occurred if the glycolysis inhibitors were added after ALA incubation, as they inhibited intracellular accumulation of photosensitiser if coincubated with ALA.

Conclusion: As 2DG and lonidamine are already used as cancer chemotherapeutic agents, our results are directly translatable to combination therapies with existing topical PDT.

A change in cellular bioenergetics, resulting in elevated metabolism and a switch towards aerobic glycolysis, is recognised as a hallmark of cancer and is correlated with tumour progression and drug resistance (Vander Heiden et al, 2009; Cairns et al, 2011; Chen, 2012). These metabolic changes promote nutrient uptake (Vander Heiden et al, 2009), overcome poor tissue oxygen supply and increased oxidative stress (Enns and Ladiges, 2012), resist apoptosis (Kroemer and Pouyssegur, 2008), and promote metastasis (Chen, 2012). This has led to an interest in targeting tumour metabolism for anticancer therapies, either by itself (Pelicano et al, 2006; Cuperlovic-Culf et al, 2012; Zhang and Yang, 2013), or in combination with radiotherapy (Coleman et al, 2008), or chemotherapy (Hernlund et al, 2008; Calvino et al, 2011). Specifically, the glycolysis inhibitors 2-deoxyglucose (2DG) (Dwarakanath, 2009), lonidamine (Brawer, 2005) and 3-bromopyruvate (3Br) (Shoshan, 2012) have all been used in clinical anticancer therapies.
Each of these glycolysis inhibitors inactivates hexokinase II (Brawer, 2005; Pelicano et al, 2006; Moreno-Sanchez et al, 2007; Scatena et al, 2008; Shoshan, 2012), although GAPDH is the preferred target of $3 \mathrm{Br}$ (Pereira da Silva et al, 2009). The inhibitors cause rapid depletion of downstream metabolites such as NADPH, pyruvate, and ATP. This disrupts tumour metabolism-dependent antioxidant defences (Trachootham et al, 2009), thereby elevating cytotoxic reactive oxygen species (ROS) (Kim et al, 2008; AykinBurns et al, 2009). Additionally, glycolysis inhibitors impair energy-dependent DNA repair and cellular recovery processes (Dwarakanath, 2009), cause cell cycle arrest (Qie et al, 2012), and initiate apoptosis by inhibiting antiapoptotic Bcl-2 family members (Ravagnan et al, 1999; Zagorodna et al, 2012). Finally, glycolysis inhibitors downregulate ABC transporters, thereby overcoming multidrug resistance (Wartenberg et al, 2010; Nakano et al, 2011).

Photodynamic therapy (PDT) is an evolving but underused treatment for cancers of the head, neck, lung, pancreas, intra-

*Correspondence: Dr JP Golding; E-mail: j.p.golding@open.ac.uk

Received 5 April 2013; revised 19 June 2013; accepted 24 June 2013; published online 16 July 2013

(c) 2013 Cancer Research UK. All rights reserved 0007-0920/13 
peritoneal cavity, breast, prostate, and skin (Bown, 2012; Milla Sanabria et al, 2012). Photodynamic therapy involves the photoactivation of a topically or systemically applied photosensitiser in the presence of oxygen, resulting in the formation of ROS, especially singlet oxygen, hydroxyl radicals, and peroxides (Milla Sanabria et al, 2012). Photodynamic therapy-induced ROS cause lipid peroxidation, crosslinking of proteins and damage to multiple cellular sites, including: membranes, DNA, and cytoskeleton (Oleinick and Evans, 1998). In addition, PDT shrinks tumour microvasculature and stimulates immune responses against the tumour (Mroz et al, 2010; Anand et al, 2012; Milla Sanabria et al, 2012).

As an adjunctive treatment, PDT has previously been combined successfully with a number of chemotherapeutic drugs, pro-oxidant agents, angiogenesis inhibitors, and immunotherapy (Zuluaga and Lange, 2008; Anand et al, 2012; Diez et al, 2012); all of which demonstrated advantages over PDT alone. Photodynamic therapy is known to deplete ATP, due to mitochondrial damage, and this may be important for initiating cytotoxicity (Ji et al, 2010). For this reason, metabolic inhibitors are a logical choice to supplement PDT. Studies of individual metabolic inhibitors: 2DG (Noodt et al, 1998; Dahle et al, 2001; Kirveliene et al, 2003) or lonidamine (Shevchuk et al, 1996) demonstrate potentiation of PDT cytotoxicity. However, there is no homogeneity in the existing data. Each study used different cell lines, different photosensitisers, and different light dose regimens. Without this direct comparison, there can be no sensible rationale for selecting the best glycolysis inhibitor to move forward clinically in combination with existing PDT. Crucially, no study has included a non-cancerous control cell type.

To resolve these questions, we have directly compared the three most promising clinical metabolic inhibitors (2DG, lonidamine and $3 \mathrm{Br}$ ), in combination with the most widely used clinical photosensitiser, for their ability to potentiate PDT cytotoxicity in vitro, both in MCF-7 cancer cells and human mammary epithelial cells (HMEC) primary breast cells.

\section{MATERIALS AND METHODS}

Unless stated otherwise, all reagents were from Sigma-Aldrich (Poole, UK).

Glycolysis inhibitors. 3-Bromopyruvate and 2DG were kept refrigerated as solids. A stock $6 \mathrm{~mm}$ ethanolic solution of lonidamine was stored at $-20^{\circ} \mathrm{C}$.

Cell cultures. Human breast adenocarcinoma cell line MCF-7 was a gift of Dr Marilena Loizidou, UCL Medical School, London (Moreno-Sanchez et al, 2007). MCF-7 cells were maintained as monolayers in RMPI 1640 medium supplemented with $100 \mu \mathrm{U} \mathrm{ml}^{-1}$ streptomycin, $100 \mu \mathrm{U} \mathrm{ml}^{-1}$ penicillin and $10 \%$ heat-inactivated fetal calf serum (FCS) at $37^{\circ} \mathrm{C}$ in a humidified $5 \% \mathrm{CO}_{2}$ atmosphere.

Normal primary HMEC were from Gibco (Paisley, UK) and maintained in the supplier's proprietary serum-free medium with $1 \%$ HMEC supplement and $50 \mu \mathrm{g} \mathrm{ml}^{-1}$ bovine pituitary extract.

Cells were seeded in 24-well plates for $24 \mathrm{~h}$ before the start of each experiment (MCF-7: 200000 cells per well; HMEC: 100000 cells per well).

Photodynamic therapy treatment. All cell washes and incubations were carried out under subdued lighting. Cells were incubated for $3 \mathrm{~h}$ with $20 \mu \mathrm{g} \mathrm{ml}^{-1}(120 \mu \mathrm{M})$ 5-aminolevulinic acid (ALA) in serum-free RPMI medium. In some experiments, cells were coincubated with ALA and glycolysis inhibitors. After ALA loading, cells were washed with PBS and maintained in phenol red-free RPMI plus 10\% FCS, with or without glycolysis inhibitors, until the end of the experiment. Cells were exposed to between 5 and $30 \mathrm{~J} \mathrm{~cm}^{-2}$ white light from a $500 \mathrm{~W}$ halogen bulb, heat-filtered through $5 \mathrm{~cm}$ of water.

Cell viability analysis. Cells were trypsinised and cell number was determined by counting in all nine major grid squares of a Neubauer Improved haemocytometer. Percentage cell death was determined by $20 \mu \mathrm{g} \mathrm{ml}^{-1}$ propidium iodide (PI) flow cytometry (FACSCalibur, Beckton Dickinson, Oxford, UK) counting 10000 gated cells per condition wherever possible (in some experiments, viability was so low that only $\sim 4000$ cells could be counted). For each condition, the total numbers of live and dead cells were calculated by combining the percentage cell death and the cell number data. Apoptosis was assessed by annexin V-FITC/PI flow cytometry of 10000 gated cells, according to the supplier's protocol (Miltenyi Biotech, Bisley, UK).

Clonogenic assay. Cells were treated with $10 \mathrm{~J} \mathrm{~cm}^{-2}$ PDT (or dark controls) and incubated for $24 \mathrm{~h}$ with glycolysis inhibitors, as detailed above. Then, 1000 live cells per condition (calculated from cell viability analysis) were added to $3 \mathrm{ml}$ RPMI $+10 \%$ FCS in poly-lysine-coated six-well plates and cultured for 9 days in the absence of glycolysis inhibitors. Wells were stained with $0.5 \% \mathrm{w} / \mathrm{v}$ methylene blue in $50 \%$ ethanol. The number of total colonies $(>2$ cells) and large colonies ( $>50$ cells) were counted per condition and photographed under identical lighting.

5-Aminolevulinic acid uptake. Cells were incubated for $5 \mathrm{~h}$ in $1 \mathrm{~mm}$ ALA plus glycolysis inhibitor, then washed with PBS and lysed with 5\% SDS. The amount of protoporphyrin IX, formed from ALA, was monitored by fluorescence spectroscopy (ex 408 nm, em 600-740 nm; Fluoromax-P, HORIBA, Stanmore, UK).

Reactive oxygen species measurements. All ROS probes were from Invitrogen (Paisley, UK). ROS levels were assayed by incubating cells for $30 \mathrm{~min}$ with either $10 \mu \mathrm{M} 2^{\prime}, 7^{\prime}$-dichlorodihydrofluorescein diacetate (DCFHDA: a general ROS probe) or $10 \mu \mathrm{M}$ dihydroethidium (DHE: a probe more sensitive to superoxides). After staining, cells were trypsinised and analysed by flow cytometry.

ATP assay. Cells were washed with PBS, then scraped into $100 \mu \mathrm{l}$ ice cold $0.5 \%$ TCA plus $1 \%$ Triton X-100, followed by $400 \mu \mathrm{l} 0.1 \mathrm{M}$ Tris $\mathrm{pH}$ 7.4. The homogenate was centrifuged and $50 \mu \mathrm{l}$ supernatant per condition aliquoted into a white 96-well plate. One-hundred microlitre Luciferase/Luciferin (ENLITEN, Promega, Southampton, UK) was added per well. Bioluminescence was measured at room temperature in a FLUOStar Optima plate reader (BMG Labtech, Aylesbury, UK) using $4 \mathrm{~s}$ integration per well.

Statistical analyses. Data were analysed by one-way ANOVA using GraphPad InStat 3.0a software (La Jolla, CA, USA). Within each category (dark or PDT) or within each time point, data were compared with the ALA-only control using Dunnett's multiple comparisons post-test. Between categories (dark vs PDT), data were compared using Bonferroni post-test. Differences were considered statistically significant at $P<0.05$. All values are reported as mean \pm s.e.m.

\section{RESULTS}

Coincubation of ALA with glycolysis inhibitors counteracts PDT cytotoxicity. In initial dose-response assays, we coincubated MCF-7 cells for $3 \mathrm{~h}$ with ALA and a range of glycolysis inhibitor concentrations. Following $30 \mathrm{~J} \mathrm{~cm}^{-2}$ PDT (or darkness), cells were incubated for $24 \mathrm{~h}$ in the presence of the same inhibitor concentration.

In the dark, only $30 \mu \mathrm{M} 3 \mathrm{Br}$ produced a significant increase in percentage cell death (24\%), compared with the no-drug control. 
All of the other inhibitor concentrations produced $<10 \%$ cell death in the dark (Figure 1A, black bars). Photodynamic therapy with ALA alone demonstrated $50 \%$ cell death (Figure 1A, white bar). Photodynamic therapy with $3 \mathrm{Br}$ demonstrated a dosedependent increase in percentage cell death up to $12 \mu \mathrm{M}$, above which percentage cell death decreased to the PDT control level. 2-Deoxyglucose and lonidamine both demonstrated dose-dependent decreases in percentage cell death following PDT, with $50 \mu \mathrm{M}$ and $300 \mu \mathrm{m}$ lonidamine both demonstrating a significant reduction in cell death compared with the PDT control (Figure 1A).

Analysis of total cell numbers (Figure 1B) produced a similar trend. Thus, PDT in the absence of glycolysis inhibitors caused a three-fold decrease in total cell number compared with the dark control. Photodynamic therapy in the presence of $3-12 \mu \mathrm{M} 3 \mathrm{Br}$ demonstrated a small but insignificant decrease in live cell numbers compared with the PDT control. However, PDT with $30 \mu \mathrm{M} 3 \mathrm{Br}$ was protective against PDT cytotoxicity and produced a significant increase in live cells and in total cell numbers compared with the PDT control. Similarly, a dose-dependent PDT protective effect was seen with 2DG and lonidamine. Importantly, the cell death-protective effect was PDT-specific; in the dark, each inhibitor demonstrated a dose-dependent decrease in live cells compared with the ALA-only control. These results were thus contradictory: by themselves, the inhibitors caused modest dose-dependent cell death, but when combined with PDT they dose-dependently reduced cell death.

Glycolysis inhibitors restrict ALA uptake. 5-Aminolevulinic acid is a pro-drug that must undergo several steps (cellular uptake, enzymatic processing) to generate the active protoporphyrin IX (ppIX) photosensitiser. Competing against this are cellular efflux pumps and enzymatic conversion of ppIX to photochemically inactive haeme. Any or all of these steps could be affected by glycolysis inhibitors, resulting in lower than expected levels of ppIX that could explain the dose-dependent decrease in PDT cytotoxicity. As ppIX has a well-defined fluorescence spectrum, we used fluorimetry to determine whether glycolysis inhibitors decrease intracellular levels of ppIX. Coincubating MCF-7 cells with ALA and glycolysis inhibitors for $5 \mathrm{~h}$, resulted in large and significant decreases in intracellular ppIX accumulation (Supplementary Figure S1). Shevchuk et al (1996) also found that lonidamine inhibited ppIX accumulation. 2-Deoxyglucose inhibits ${ }^{14}[\mathrm{C}]$-labelled ALA uptake in WiDr colon cancer cells (Gederaas et al, 2001) and if this occurs with other glycolysis inhibitors, it could explain the lower ppIX accumulation.

Glycolysis inhibition after ALA loading strongly potentiates PDT cytotoxicity. In contrast to the PDT protective effect seen when cells were coincubated with ALA and glycolysis inhibitors, we found a robust increase in PDT-induced cytotoxicity (more than three-fold above ALA-only), at a range of light doses, when $180 \mathrm{~mm} 2 \mathrm{DG}$ or $300 \mu \mathrm{M}$ lonidamine (but not $12 \mu \mathrm{M} 3 \mathrm{Br}$ ) was added after ALA loading (Figure 2A and B). For these experiments, inhibitors were added $15 \mathrm{~min}$ before PDT and maintained for $24 \mathrm{~h}$.

We next investigated how the duration of glycolysis inhibition affected PDT cytotoxicity at $24 \mathrm{~h}$. Acute application of glycolysis inhibitors (for $1 \mathrm{~h}, 2 \mathrm{~h}$, or $24 \mathrm{~h}$ ) immediately after $10 \mathrm{~J} \mathrm{~cm}^{-2}$ PDT yielded gradual increases in MCF-7 cytotoxicity with lonidamine. Conversely, 2DG was initially protective against PDT when applied for 1 or $2 \mathrm{~h}$, but strongly potentiated PDT cytotoxicity if applied for $24 \mathrm{~h}$ (Figure 2C and D). In subsequent experiments, we added $180 \mathrm{~mm} 2 \mathrm{DG}$ or $300 \mu \mathrm{m}$ lonidamine immediately after PDT for $24 \mathrm{~h}$. We also settled on $10 \mathrm{~J} \mathrm{~cm}^{-2}$ as our standard PDT light dose. As $12 \mu \mathrm{M} 3 \mathrm{Br}$ had no PDT potentiating effect when added after PDT, we excluded it from further study in MCF-7 cells.

Acute glycolysis inhibition following PDT compromises MCF-7 long-term survival. Following acute $(24 \mathrm{~h})$ exposure to glycolysis inhibitors, clonogenic assays of surviving cells were used to test MCF-7 long-term survival and proliferative ability. Comparing PDT with corresponding dark-treated cells, there were 1.9-fold fewer colonies in no-drug controls, 2.6-fold fewer colonies in acute 2DG-treated cells, and 10.1-fold fewer colonies in acute lonidamine treated cells (Figure 2E and F).
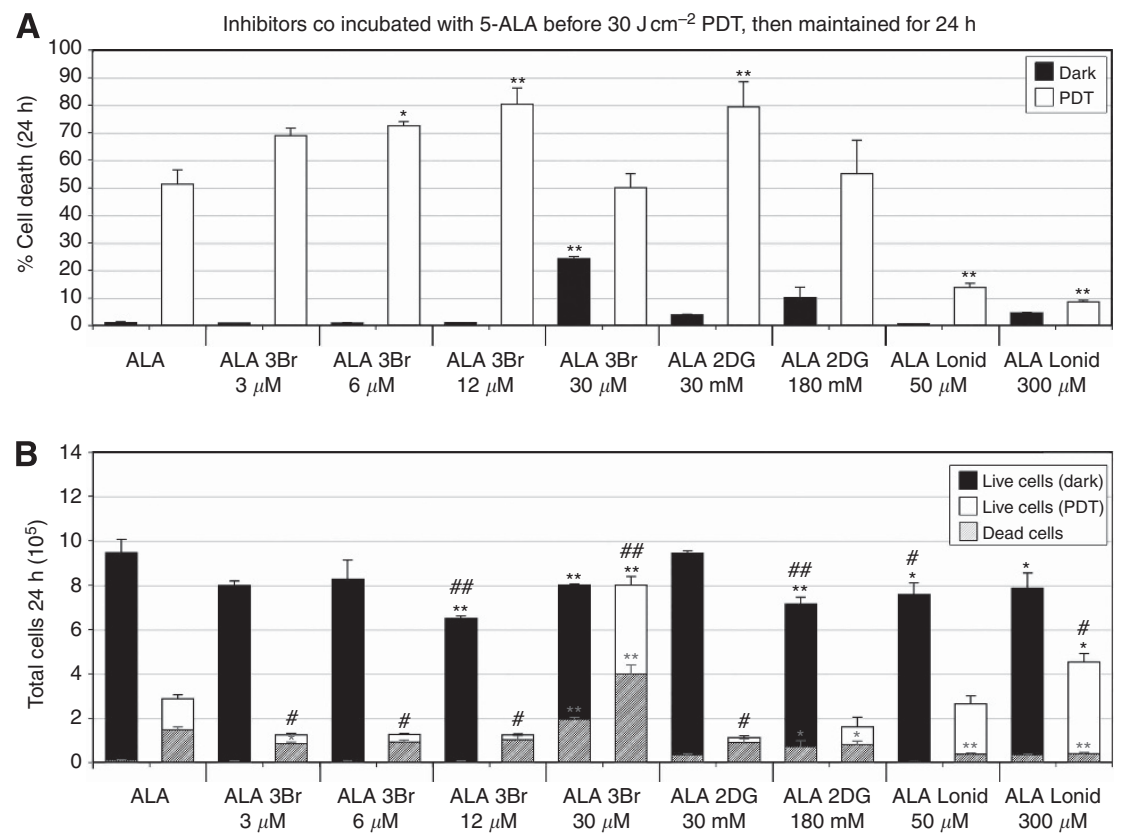

Figure 1. Coincubation of ALA with glycolysis inhibitors causes dose-dependent cytotoxicity in the dark (black bars) but dose-dependent death protection following $30 \mathrm{~J} \mathrm{~cm}^{-2}$ PDT (white bars). (A) Percentage cell death. (B) Total cell numbers per well, subdivided into live cells and dead cells for each condition. Significant differences, compared with ALA-only controls, are denoted by $* P<0.05$, ** $P<0.01$ for live cells or dead cells, and ${ }^{\#} P<0.05,{ }^{\# \#} P<0.01$ for total cells. 

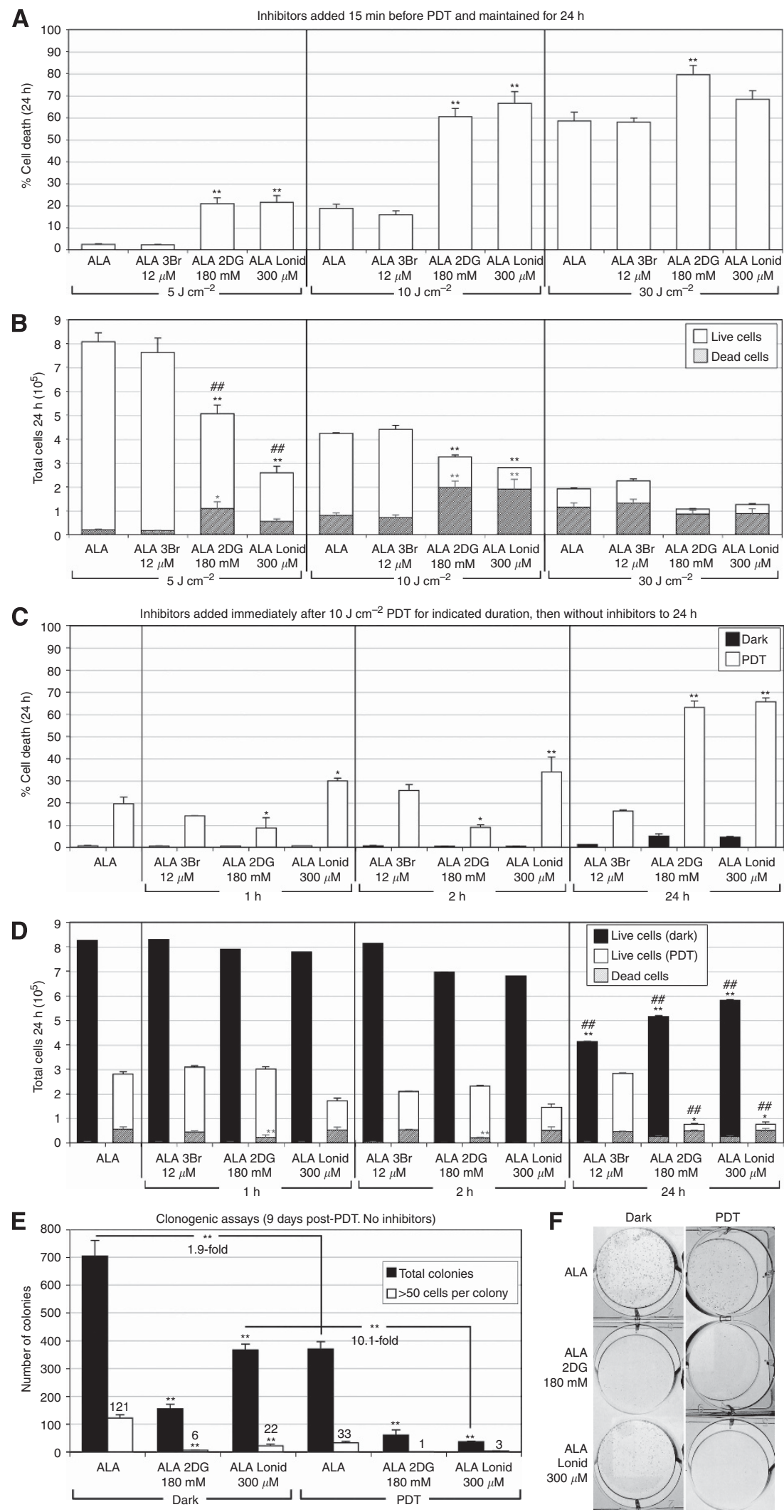

Figure 2. Effect of different light doses and inhibitor application times on MCF-7 viability. (A, B) Inhibitors added 15 min before PDT and maintained for $24 \mathrm{~h}$. (A) Percentage cell death and (B) Total cell number, subdivided into live cells (white area) and dead cells (shaded area). (C, D) Acute application of inhibitors post-PDT, subsequently maintained to $24 \mathrm{~h}$ without inhibitors. (C) Percentage cell death and (D) Total cell number, subdivided into live and dead cells. (E, F) Clonogenic assays. Following PDT and $24 \mathrm{~h}$ exposure to glycolysis inhibitors, 1000 live cells per condition were maintained in the absence of inhibitors for 9 days. (E) Dark bars show total colonies formed ( $>2$ cells); white bars show colonies larger than 50 cells. (F) Photo-montage of clonogenic assay from E. Significant differences, compared with ALA-only controls, are denoted by ${ }^{\star} P<0.05,{ }^{\star \star} P<0.01$ for live cells or dead cells, and ${ }^{\#} P<0.05,{ }^{\# \#} P<0.01$ for total cells. 
Mechanisms of glycolysis inhibition-augmented PDT cytotoxicity. We examined the time-courses of: cell death, ROS generation and ATP depletion for up to $4.5 \mathrm{~h}$ after PDT.

Cell death. In the dark, all conditions demonstrated a consistent and low $(<7 \%)$ cytotoxicity, with $2 \mathrm{DG}$ or lonidamine being significantly more cytotoxic than the no-inhibitor control (Figure 3A). Within $90 \mathrm{~min}$ of PDT, lonidamine significantly increased percentage cell death to $20 \%$. Cell death was maintained at this level until the end of the observation period $(270 \mathrm{~min})$. By contrast, PDT followed by 2DG incubation demonstrated less cell death than the control at $90 \mathrm{~min}$, although death increased to above control levels by $270 \mathrm{~min}$ (Figure 3A).

Apoptosis was assessed at $2 \mathrm{~h}$ and $4 \mathrm{~h}$ post-PDT (or darkness, for controls) using Annexin V-FITC/PI FACS. For this experiment, PDT was performed at $15 \mathrm{~J} \mathrm{~cm}^{-2}$ to improve the annexin $\mathrm{V}$ detection rate for statistical analysis. Cell death was associated with increased apoptosis for PDT with lonidamine, but not for PDT with 2DG, suggesting distinct initial cell death mechanisms (Figure 3B).

Reactive oxygen species levels. Reactive oxygen species levels were assayed every $30 \mathrm{~min}$ from immediately after PDT to $270 \mathrm{~min}$ later, using a fluorogenic probe sensitive to most ROS species (DCFHDA) or to superoxides (DHE) (Figure 3C and D). At each time point and with either probe, ROS levels generally followed the order: lonidamine $>$ control $>2$ DG (Figure $3 \mathrm{C}$ and D). Unexpectedly, ROS levels in the presence of $2 \mathrm{DG}$ were consistently much lower than no-drug controls, which was counterintuitive considering how well 2DG enhanced PDT cytotoxicity (Figure 2). We wondered if the apparent low ROS levels with 2DG could be an artefactual consequence of lower probe uptake or impaired processing by intracellular esterases, unrelated to the actual ROS levels. We used the ROS-insensitive positive control probe, carboxy-DCFDA $(10 \mu \mathrm{M})$, to monitor probe accumulation during $30 \mathrm{~min}$, and found this was 2.6-fold lower in the presence of 2DG, suggesting that ROS levels with 2DG (in Figure 3C) likely did exceed no-drug control levels.

ATP levels. Glycolysis inhibitors caused rapid (within $30 \mathrm{~min}$ ) and stable (to $2 \mathrm{~h}$ after application) depletion of ATP levels compared with ALA-only controls (Figure 4A). The ATP concentration always followed the sequence control $>$ lonidamine $>2$ DG. Moreover, ATP levels following PDT were always lower than corresponding dark controls (Figure 4A).

Glycolysis inhibition potentiates PDT cytotoxicity selectively in cancer cells. Photodynamic therapy cytotoxicity was examined in normal primary HMEC, with inhibitors added $15 \mathrm{~min}$ before $10 \mathrm{~J} \mathrm{~cm}^{-2}$ PDT and maintained for $24 \mathrm{~h}$. In contrast to the results with MCF-7 cells (Figure 2A and C), each inhibitor caused $<10 \%$ cell death in HMEC following PDT (Figure 5A), while dark toxicity was similar to that in MCF-7 cells (Figure 1A; Figure 2C). Photodynamic therapy showed a (non-significant) trend of reducing the number of live HMEC compared with dark controls (Figure 5B). However, the magnitude of this decrease was much smaller than that observed with MCF-7 cells (Figure 2D).
A

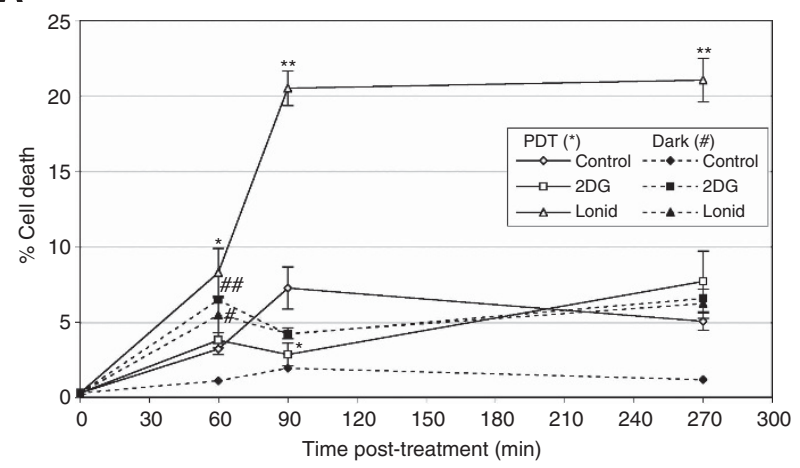

C

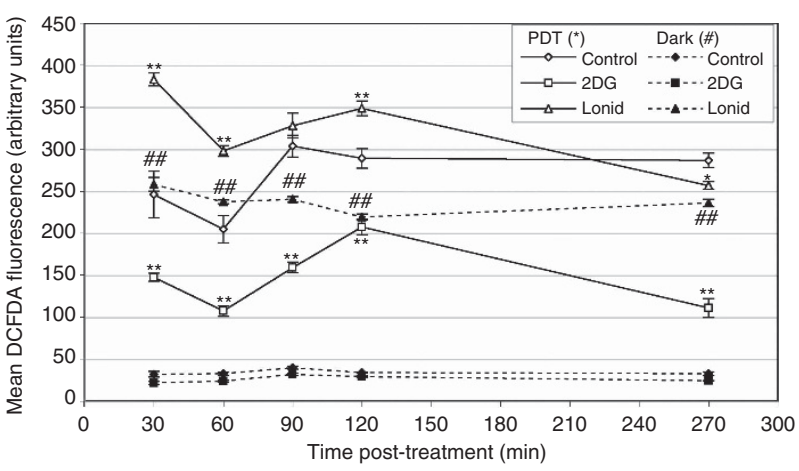

B
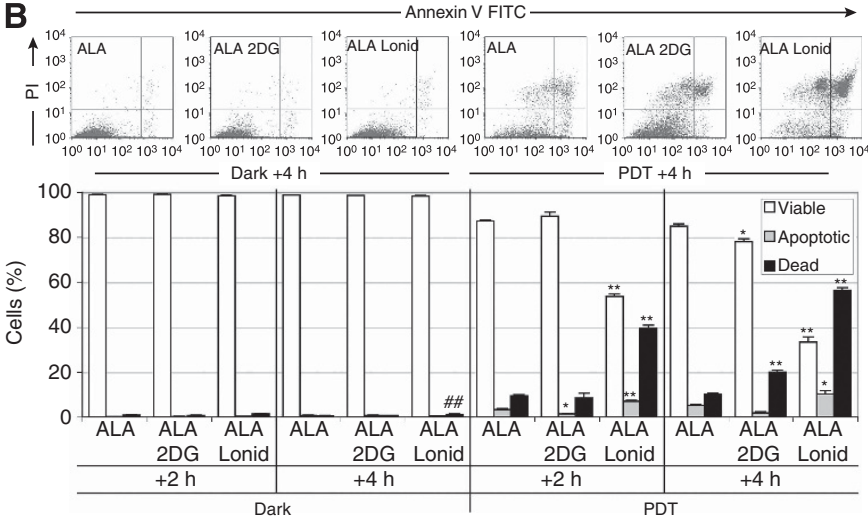

D

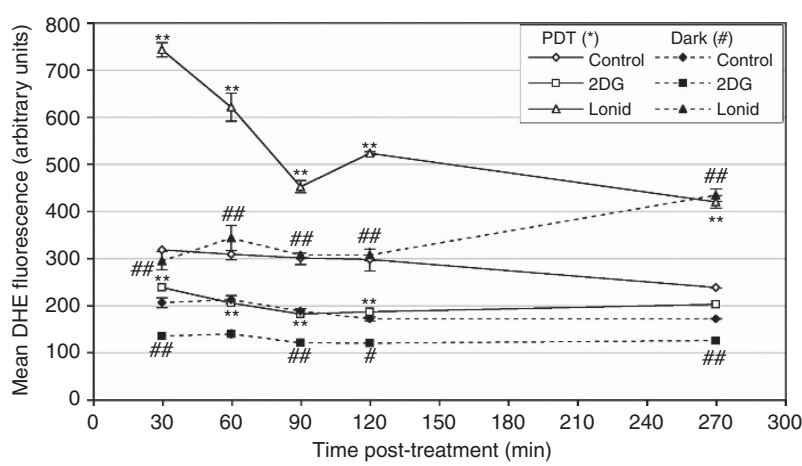

Figure 3. Short-term (30-270 min) time-courses. (A) MCF-7 cell death (PI positive cells). (B) Apoptosis (annexin V positive cells). In B, representative scatter plots show the distribution of Annexin V-FITC and Pl-stained cells. Cells are classified as 'live' (bottom left), 'dead' (top left plus top right), and 'apoptotic' (bottom right). Bar charts below show quantitative analysis of scatter plots. (C) Reactive oxygen species levels (DCFDA fluorescence). (D) Superoxide levels (DHE fluorescence). Significant differences, compared with ALA-only controls, are denoted by * $P<0.05$, ${ }^{\star \star} P<0.01$ for PDT-treated cells, and ${ }^{\#} P<0.05,{ }^{\# \#} P<0.01$ for dark-maintained cells. 


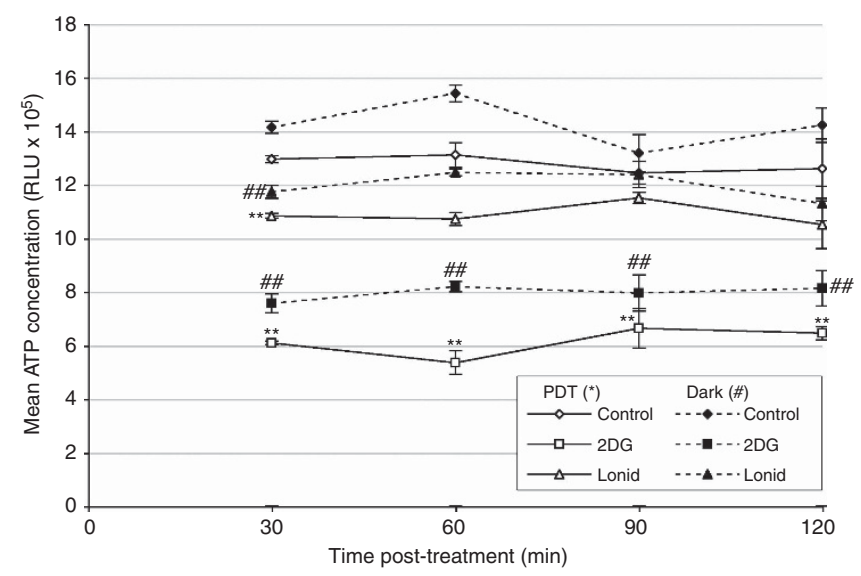

Figure 4. Short-term (30-120 min) time-course of intracellular ATP concentration in MCF-7 cells. Significant differences, compared with ALA-only controls, are denoted by ${ }^{\star} P<0.05,{ }^{\star \star} P<0.01$ for PDT-treated cells, and ${ }^{\#} P<0.05,{ }^{\# \#} P<0.01$ for dark-maintained cells.
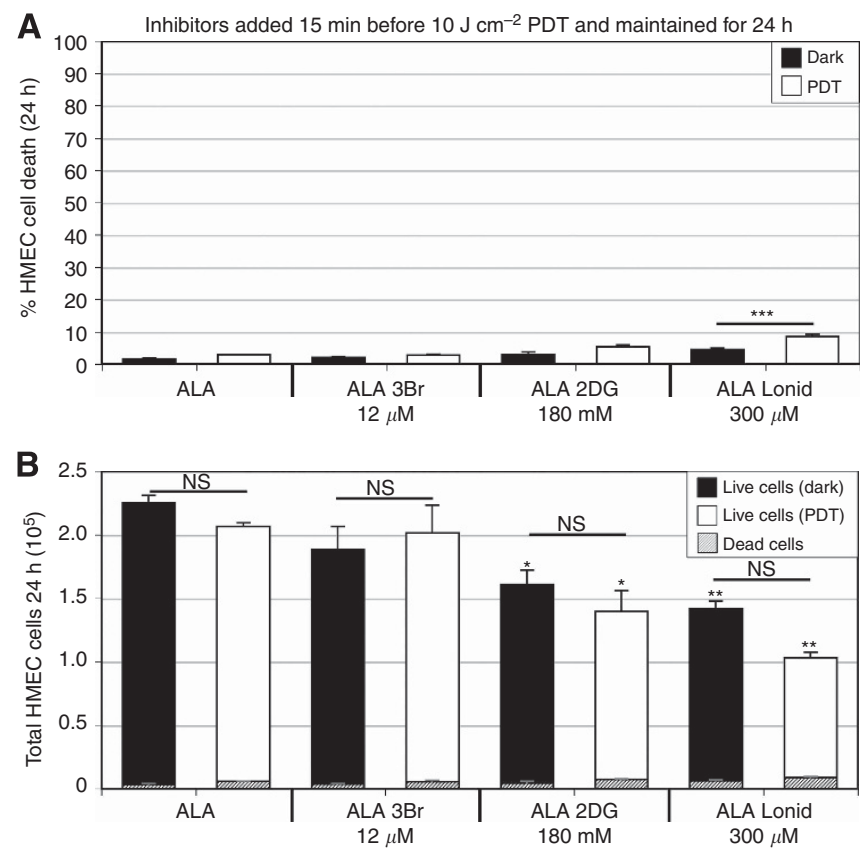

Figure 5. Effect of glycolysis inhibitors and $10 \mathrm{~J} \mathrm{~cm}^{-2}$ PDT on HMEC cytotoxicity. (A) Percentage cell death and (B) total cell number, subdivided into live and dead cells. Significant differences, compared with ALA-only controls, are denoted by ${ }^{\star} P<0.05$, ${ }^{\star \star} P<0.01$, $\star \star \star P<0.001$

\section{DISCUSSION}

Increased metabolism and a shift towards aerobic glycolysis are hallmarks of cancer, making this pathway an attractive clinical target. Previous work has demonstrated that 2DG (Noodt et al, 1998; Dahle et al, 2001; Kirveliene et al, 2003), and lonidamine (Shevchuk et al, 1996) can potentiate PDT cytotoxicity. However, this is the first study to directly compare three clinical glycolysis inhibitors, their optimum application times and light doses. We show that acute glycolysis inhibition by $<\mathrm{LD}_{10}$ concentrations of 2DG or lonidamine, during or just after ALA PDT, results in more than a three-fold increase in MCF-7 cytotoxicity after $24 \mathrm{~h}$. By contrast, $12 \mu \mathrm{M} 3 \mathrm{Br}$ only potentiated PDT cytotoxicity when coadministered with ALA, although it depleted ATP levels to a similar extent as $300 \mu \mathrm{M}$ lonidamine (Supplementary Figure S2), suggesting that ATP depletion by itself is insufficient to increase PDT cytotoxicity.

On a molar basis, lonidamine was more effective than 2DG at potentiating PDT.

Although lonidamine is tolerated at $300 \mu \mathrm{M}$ in vitro, it has only been tested systemically in humans at up to $127 \mu \mathrm{M}$ (Gatzemeier et al, 1991). Despite this, high concentrations of 2DG or lonidamine may prove clinically relevant for topical PDT (e.g., $300 \mathrm{~mm}$ 2DG is tolerated topically (Kern et al, 1982)).

The improved PDT cytotoxicity with 2DG or lonidamine is selective towards MCF-7 breast cancer cells, compared with HMEC primary breast cells, and is optimal at low light doses $\left(5-10 \mathrm{Jcm}^{-2}\right)$. Glycolysis inhibition plus PDT is cytotoxic rather than cytostatic, as a continued decrease in cell viability was seen after removal of glycolysis inhibitors, with up to a 10 -fold increase in cytotoxicity compared with dark controls seen in 9-day clonogenic assays.

Although the extent of MCF-7 cell death was similar with 2DG or lonidamine $24 \mathrm{~h}$ after PDT, differences were apparent in their initial PDT cytotoxicity that suggest distinct cell death mechanisms. Lonidamine demonstrated initially higher levels of PDT-induced ROS, a faster onset of cytotoxicity, and significant apoptosis compared with 2DG (Figure 3). By contrast, 2DG depleted ATP levels more than lonidamine (Figure 4) and had a slower onset of PDT cytotoxicity, beginning around $4 \mathrm{~h}$ after PDT (Figure $3 \mathrm{~A}$ ), which was probably necrotic, as it was not associated with elevated apoptosis (Figure $3 \mathrm{~B}$ ). ATP is required to initiate apoptosis (Reubold and Eschenburg, 2012), and in our experiments 2DG perhaps depletes ATP below this critical threshold. A previous study (Oberdanner et al, 2002) similarly demonstrated that inhibiting glycolysis (using glucose-free media) prevented PDT-induced apoptosis.

To facilitate translation of this work, we deliberately chose clinically validated (phase II/III) glycolysis inhibitors, for which the posology and safety characteristics are already known, and one of the most popular clinically licensed photosensitisers (Brawer, 2005; Morton et al, 2008; Dwarakanath, 2009). By using existing systemic drug regimens, we propose that tumours could immediately be treated by conventional PDT, followed by acute $24 \mathrm{~h}$ glycolysis inhibition, the combination therapy being more effective than either treatment alone. In the longer term, depending on successful clinical testing, we propose that higher doses of glycolysis inhibitors, similar to those we use here, could be applied locally and topically for improved treatment of skin cancers and pre-cancers, for which PDT is already recommended (Morton et al, 2008).

REFERENCES

Anand S, Ortel BJ, Pereira SP, Hasan T, Maytin EV (2012) Biomodulatory approaches to photodynamic therapy for solid tumors. Cancer Lett 326: $8-16$.

Aykin-Burns N, Ahmad IM, Zhu Y, Oberley LW, Spitz DR (2009) Increased levels of superoxide and $\mathrm{H}_{2} \mathrm{O}_{2}$ mediate the differential susceptibility of cancer cells versus normal cells to glucose deprivation. Biochem J 418: 29-37.

Bown SG (2012) How mainstream medicine sees photodynamic therapy in the United Kingdom. J Natl Compr Canc Netw 10(Suppl 2): S69-S74.

Brawer MK (2005) Lonidamine: basic science and rationale for treatment of prostatic proliferative disorders. Rev Urol 7(Suppl 7): S21-S26.

Cairns RA, Harris IS, Mak TW (2011) Regulation of cancer cell metabolism. Nat Rev Cancer 11: 85-95. 
Calvino E, Estan MC, Simon GP, Sancho P, Boyano-Adanez Mdel C, de Blas E, Breard J, Aller P (2011) Increased apoptotic efficacy of lonidamine plus arsenic trioxide combination in human leukemia cells. Reactive oxygen species generation and defensive protein kinase (MEK/ERK, Akt/mTOR) modulation. Biochem Pharmacol 82: 1619-1629.

Chen EI (2012) Mitochondrial dysfunction and cancer metastasis. J Bioenerg Biomembr 44: 619-622.

Coleman MC, Asbury CR, Daniels D, Du J, Aykin-Burns N, Smith BJ, Li L, Spitz DR, Cullen JJ (2008) 2-deoxy-D-glucose causes cytotoxicity, oxidative stress, and radiosensitization in pancreatic cancer. Free Radic Biol Med 44: 322-331.

Cuperlovic-Culf M, Culf A, Touaibia M, Lefort N (2012) Targeting the latest hallmark of cancer: another attempt at 'magic bullet' drugs targeting cancers' metabolic phenotype. Future Oncol 8: 1315-1330.

Dahle J, Angell-Petersen E, Steen HB, Moan J (2001) Bystander effects in cell death induced by photodynamic treatment UVA radiation and inhibitors of ATP synthesis. Photochem Photobiol 73: 378-387.

Diez B, Ernst G, Teijo MJ, Batlle A, Hajos S, Fukuda H (2012) Combined chemotherapy and ALA-based photodynamic therapy in leukemic murine cells. Leuk Res 36: 1179-1184.

Dwarakanath BS (2009) Cytotoxicity, radiosensitization, and chemosensitization of tumor cells by 2-deoxy-D-glucose in vitro. J Cancer Res Ther 5(Suppl 1): S27-S31.

Enns L, Ladiges W (2012) Mitochondrial redox signaling and cancer invasiveness. J Bioenerg Biomembr 44: 635-638.

Gatzemeier U, Toomes H, Picollo R, Christoffel V, Lucker PW, Ulmer J (1991) Single- and multiple dose pharmacokinetics of lonidamine in patients suffering from non-small-cell lung cancer. Arzneimittelforschung 41: 436-439.

Gederaas OA, Holroyd A, Brown SB, Vernon D, Moan J, Berg K (2001) 5-Aminolaevulinic acid methyl ester transport on amino acid carriers in a human colon adenocarcinoma cell line. Photochem Photobiol 73: 164-169.

Hernlund E, Ihrlund LS, Khan O, Ates YO, Linder S, Panaretakis T, Shoshan MC (2008) Potentiation of chemotherapeutic drugs by energy metabolism inhibitors 2-deoxyglucose and etomoxir. Int J Cancer 123: 476-483.

Ji HT, Chien LT, Lin YH, Chien HF, Chen CT (2010) 5-ALA mediated photodynamic therapy induces autophagic cell death via AMP-activated protein kinase. Mol Cancer 9: 91.

Kern ER, Glasgow LA, Klein RJ, Friedman-Kien AE (1982) Failure of 2-deoxyD-glucose in the treatment of experimental cutaneous and genital infections due to herpes simplex virus. J Infect Dis 146: 159-166.

Kim JS, Ahn KJ, Kim JA, Kim HM, Lee JD, Lee JM, Kim SJ, Park JH (2008) Role of reactive oxygen species-mediated mitochondrial dysregulation in 3-bromopyruvate induced cell death in hepatoma cells: ROS-mediated cell death by 3-BrPA. J Bioenerg Biomembr 40: 607-618.

Kirveliene V, Sadauskaite A, Kadziauskas J, Sasnauskiene S, Juodka B (2003) Correlation of death modes of photosensitized cells with intracellular ATP concentration. FEBS Lett 553: 167-172.

Kroemer G, Pouyssegur J (2008) Tumor cell metabolism: cancer's Achilles' heel. Cancer Cell 13: 472-482.

Milla Sanabria L, Rodriguez ME, Cogno IS, Rumie Vittar NB, Pansa MF, Lamberti MJ, Rivarola VA (2012) Direct and indirect photodynamic therapy effects on the cellular and molecular components of the tumor microenvironment. Biochim Biophys Acta 1835: 36-45.

Moreno-Sanchez R, Rodriguez-Enriquez S, Marin-Hernandez A, Saavedra E (2007) Energy metabolism in tumor cells. Febs J 274: 1393-1418.

Morton CA, McKenna KE, Rhodes LE (2008) Guidelines for topical photodynamic therapy: update. Br J Dermatol 159: 1245-1266.

Mroz P, Szokalska A, Wu MX, Hamblin MR (2010) Photodynamic therapy of tumors can lead to development of systemic antigen-specific immune response. PLoS One 5: e15194.
Nakano A, Tsuji D, Miki H, Cui Q, El Sayed SM, Ikegame A, Oda A, Amou H, Nakamura S, Harada T, Fujii S, Kagawa K, Takeuchi K, Sakai A, Ozaki S, Okano K, Nakamura T, Itoh K, Matsumoto T, Abe M (2011) Glycolysis inhibition inactivates $\mathrm{ABC}$ transporters to restore drug sensitivity in malignant cells. PLoS One 6: e27222.

Noodt BB, Rodal GH, Wainwright M, Peng Q, Horobin R, Nesland JM, Berg K (1998) Apoptosis induction by different pathways with methylene blue derivative and light from mitochondrial sites in V79 cells. Int J Cancer 75: 941-948.

Oberdanner CB, Kiesslich T, Krammer B, Plaetzer K (2002) Glucose is required to maintain high $\mathrm{ATP}$-levels for the energy-utilizing steps during PDT-induced apoptosis. Photochem Photobiol 76: 695-703.

Oleinick NL, Evans HH (1998) The photobiology of photodynamic therapy: cellular targets and mechanisms. Radiat Res 150: S146-S156.

Pelicano H, Martin DS, Xu RH, Huang P (2006) Glycolysis inhibition for anticancer treatment. Oncogene 25: 4633-4646.

Pereira da Silva AP, El-Bacha T, Kyaw N, dos Santos RS, da-Silva WS, Almeida FC, Da Poian AT, Galina A (2009) Inhibition of energyproducing pathways of HepG2 cells by 3-bromopyruvate. Biochem J 417: 717-726.

Qie S, Liang D, Yin C, Gu W, Meng M, Wang C, Sang N (2012) Glutamine depletion and glucose depletion trigger growth inhibition via distinctive gene expression reprogramming. Cell Cycle 11: 3679-3690.

Ravagnan L, Marzo I, Costantini P, Susin SA, Zamzami N, Petit PX, Hirsch F, Goulbern M, Poupon MF, Miccoli L, Xie Z, Reed JC, Kroemer G (1999) Lonidamine triggers apoptosis via a direct, Bcl-2-inhibited effect on the mitochondrial permeability transition pore. Oncogene 18: 2537-2546.

Reubold TF, Eschenburg S (2012) A molecular view on signal transduction by the apoptosome. Cell Signal 24: 1420-1425.

Scatena R, Bottoni P, Pontoglio A, Mastrototaro L, Giardina B (2008) Glycolytic enzyme inhibitors in cancer treatment. Expert Opin Investig Drugs 17: 1533-1545.

Shevchuk I, Chekulayev V, Moan J, Berg K (1996) Effects of the inhibitors of energy metabolism, lonidamine and levamisole, on 5-aminolevulinic-acidinduced photochemotherapy. Int J Cancer 67: 791-799.

Shoshan MC (2012) 3-Bromopyruvate: targets and outcomes. J Bioenerg Biomembr 44: 7-15.

Trachootham D, Alexandre J, Huang P (2009) Targeting cancer cells by ROS-mediated mechanisms: a radical therapeutic approach? Nat Rev Drug Discov 8: 579-591.

Vander Heiden MG, Cantley LC, Thompson CB (2009) Understanding the Warburg effect: the metabolic requirements of cell proliferation. Science 324: 1029-1033.

Wartenberg M, Richter M, Datchev A, Gunther S, Milosevic N, Bekhite MM, Figulla HR, Aran JM, Petriz J, Sauer H (2010) Glycolytic pyruvate regulates P-Glycoprotein expression in multicellular tumor spheroids via modulation of the intracellular redox state. J Cell Biochem 109: 434-446.

Zagorodna O, Martin SM, Rutkowski DT, Kuwana T, Spitz DR, Knudson CM (2012) 2-deoxyglucose-induced toxicity is regulated by Bcl-2 family members and is enhanced by antagonizing Bcl-2 in lymphoma cell lines. Oncogene 31: 2738-2749.

Zhang Y, Yang JM (2013) Altered energy metabolism in cancer: A unique opportunity for therapeutic intervention. Cancer Biol Ther 14: 81-89.

Zuluaga MF, Lange N (2008) Combination of photodynamic therapy with anti-cancer agents. Curr Med Chem 15: 1655-1673.

This work is published under the standard license to publish agreement. After 12 months the work will become freely available and the license terms will switch to a Creative Commons AttributionNonCommercial-Share Alike 3.0 Unported License.

Supplementary Information accompanies this paper on British Journal of Cancer website (http://www.nature.com/bjc) 